\title{
Sex selection and health at birth among Indian immigrants
}

\author{
Libertad González* \\ Universitat Pompeu Fabra and Barcelona GSE
}

March 2016

\begin{abstract}
I use birth-certificate data for Spain to document extremely son-biased sex ratios at birth among Indian immigrants. I also show that the children of Indian immigrants display poor health outcomes during infancy, although there is no evidence of a gender gap in infant health. I provide evidence suggesting that the poor outcomes of Indian children at birth can be attributed to the low health endowments of Indian mothers, while the absence of a gender gap is driven by the fact that the parents who would invest less in girls are less likely to carry the pregnancies of girls to term (more likely to practice sex-selective abortion).

JEL codes: J13, I15
\end{abstract}

Keywords: fertility, sex ratio, abortion, sex selection, son preference, infant health, immigration, India, Spain.

\footnotetext{
* I thank Alessandro Tarozzi for his useful comments. This research was funded by Spanish government grant number ECO2014-55555-P.
} 


\section{Introduction}

In two influential papers in the early 1990's, Amartya Sen $(1990,1992)$ raised attention to the high male to female ratios prevalent in India and other Asian and North-African countries, attributing them to excess mortality among women, which he suggested might derive from the comparative neglect of female health. Since then, a new trend emerged in the same countries, with increasingly son-biased sex ratios at birth. Sen (2003) attributed this new trend to parental preferences for boys, combined with the availability of sex determination technologies and sex-selective abortion. These findings were confirmed in later work by Jha et al. (2006), Bhalotra \& Cochrane (2010), and Bongaarts \& Guilmoto (2015), among others. ${ }^{1}$

A related literature has documented the poor health of Indian children, relative to international standards (and to countries with similar income levels), see for example Deaton and Drèze (2009) and Tarozzi (2008, 2012). The limited available evidence indicates that this gap is probably not due to genetic factors (Tarozzi 2008). The poor health of Indian mothers is almost certainly a contributing factor (Coffey 2015). Recent work by Jayachandran \& Pande (2015) also suggests that at least some of the gap might be explained by parental preferences for the first son (so that girls and higher-parity boys receive lower parental investments and are thus less healthy).

While a number of papers failed to find direct evidence of lower parental (postnatal) investments in girls in India (such as nutrient intake), recent work suggests that some of the mortality gender gap is probably related to girls getting breastfed less than boys (Jayachandran \& Kumzienko 2010; Barcellos, Carvalho \& Lleras-Muney 2014), as well as to gender gaps in vaccination and malnutrition (Oster 2009a, 2009b). Recent evidence also points to the role played by differential prenatal investments, such as tetanus shots during pregnancy (Bharadwaj \& Lakdawale 2013).

Another related strand of literature has studied Indian immigrants residing in other countries. Male to female sex ratios at birth have been found to be high (and increasing in recent decades) among Indian immigrants in the UK (Dubuc \& Coleman 2007), the US (Abrevaya 2009, Almond \& Edlund 2010) and Canada (Almond et al. 2013). As is

\footnotetext{
${ }^{1}$ Recent estimates suggest that since 1990, the number of "missing women" in the world has risen by 43 percent to 126 million in 2010, and are projected to continue increasing (Bongaarts \& Guilmoto 2015).
} 
the case in India, the son-biased sex ratios are driven by higher-order births and families with no previous boys.

Not so much is known about the health of children of Indian descent residing in rich countries (at birth or later on), although some (limited) evidence has been provided of assimilation in health with time in the host country (Proos 1992). Tarozzi (2008) shows that ethnic Indian children in the UK are as healthy as native children, with some evidence of assimilation with time in the host country, although the data limitations are severe (his sample includes only 471 ethnic Indian children, aged 2-18).

Also due to data limitations, little is known about the gender gap in health at birth (and its determinants) among Indian children (in India or elsewhere). ${ }^{2}$ This makes it hard to separate the influence of pre-natal and post-natal parental investments as contributors to the differential mortality rates.

In this paper, I first confirm the results in previous studies for other host countries, showing evidence of severely son-biased sex ratios at birth among Indian immigrants, using high-quality birth register data for Spain. This bias is also found to increase with birth-order, and is much more pronounced for India than for any other source country.

I am able to rule out that the "missing girls" can be traced to differential stillbirth rates: I find that the pregnancies of Indian mothers are not significantly more likely to end in stillbirth than other immigrant groups, and Indian women carrying girls are no more likely to suffer a stillbirth than those carrying boys.

Then, I take advantage of the rich measures of health at birth to study the health of the children of Indian immigrants at birth. I show that the children of Indian parents are (much) less healthy than natives as well as other immigrant groups at birth (in terms of prematurity rates, birth-weight, etc), but there is no gender gap: newborn Indian girls are no less healthy than boys. This pattern remains when I analyze infant and child mortality. To my knowledge, this is the first estimate of the gender gap in health at birth among the children of Indian immigrants anywhere.

\footnotetext{
${ }^{2}$ This is due to the long-recognized low quality of birth registers in India, as well as the absence of large-sample nationally representative data sets that include measures of health at birth (such as birth-weight). Probably the best available data source is the National Family Health Survey (NFHS), which included almost 9,000 observations of children under age 1 (less than 500 under one month) in the 2005-06 wave. Birth-weight is reported for children under age 5, but the non-response rate is very high (66\%).
} 
I then link both sets of results and provide a simple framework to interpret the documented health gaps in terms of a combination of selection via abortion of girls, the poor socioeconomic and health status of Indian mothers, and differential prenatal investments in boys versus girls. First, I show that the poor health of Indian boys is probably a direct result of the poor endowments of India-born mothers. Then, I show evidence consistent with the absence of a gender gap in newborn and infant health among the children of Indian parents being plausibly driven by positive selection in (potential) pre-natal investments, such that the parents with a stronger preference for boys, who would thus invest less in girls, are less likely to carry the pregnancy of a girl to term.

This study links the literature on sex ratios at birth (in India or among Indian immigrants) with the one on the health of Indian children, and the high mortality rates among Indian girls, focusing on health at birth. I also add to a small number of recent papers (Hu \& Schlosser 2015; Lin, Liu \& Qian 2014) that highlight the fact that selective abortion of girls may have direct implications for the (relative) health of (surviving) girls. The strategy to link sex ratios at birth to the health of girls in those papers is to compare children in time periods and/or regions with lower versus higher incidence of sex selective abortion. Instead, I use as "controls" groups of parents with no son preference (as reflected in balanced sex ratios at birth), based on country of birth. I am also able to study health outcomes not available in previous studies, such as prematurity and birth-weight, which have been shown to have important long-term consequences, and which are only affected by pre-natal (versus post-natal) parental investments.

The remainder of the paper is organized as follows. Section 2 describes the data sources. My main data source is Spanish birth-certificate micro data for years 20072013. The universe of singleton registered live births is $3,209,697$, out of which 4,419 have at least one parent born in India or holding Indian citizenship. I combine this data set with death-certificate data for the analysis of child mortality. The following section documents extremely biased sex ratios at birth among Indian immigrants, compared to natives as well as other immigrant groups. The bias is shown to increase with birthorder, and to be less pronounced among Indian-born parents holding Spanish citizenship or married to a native. Then, section 4 evaluates a number of measures of health at birth, showing that the children of Indian parents are less healthy at birth than the children of 
natives or other immigrants, but the gap is no more pronounced for girls than for boys. This pattern is shown to remain when the outcome variable is neonatal, infant or child mortality. Section 5 interprets the health results as a function of parental endowments, investments, and selection, taking into account that the families that end a pregnancy when carrying a girl may not be random, and section 6 concludes.

\section{Data}

I use Spanish birth-certificate data, made available publicly by the Spanish National Statistical Institute (INE). They record information on each registered birth in Spain, including baby as well as family characteristics. ${ }^{3}$ I focus on years 2007-2013, since the country of birth of the parents was not recorded before 2007 (although the country of citizenship was). I restrict the sample to singleton births, because even though multiple births represent a small fraction of the total (slightly under $2 \%$ ), their high prematurity rates and low weight at birth can affect average measures of health at birth disproportionately. I also drop stillbirths from the main sample (although I look at stillbirths separately as an outcome). My main sample includes all 3,209,697 singleton registered live births in Spain between 2007 and 2013 (the last year of data available at the time of writing).

About $27 \%$ of all newborns in the sample have at least one foreign-born parent (17.5\% have both parents born outside of Spain), and 1.6\% (over 52,000 births) have at least one parent born in Asia (1.4\% both parents). Within Asia, the most common immigrant group among new parents is by far China (63\%), followed by Pakistan (16\%) and India and the Philippines (8\% each). There are 4,357 newborns with at least one parent born in India, and 3,344 with both parents born in India. Outside of Asia, the most common source countries among new mothers are Morocco (27\% of all births to immigrant parents), Romania (11\%) and Ecuador (8\%).

As measures of health at birth, I use: weeks of gestation at birth, prematurity, (log) birth-weight, low birth-weight (below 2,500 grams) and very low birth-weight (below 1,500 grams) indicators, as well as first-day mortality (during the 24 hours following birth). In the full sample, average weeks of gestation are 39, while $6 \%$ of newborns

3 There is no information on sub-national region of origin, religion, years since migration, or sex of the previous children. 
weigh less than 2,500 grams at birth, and 5 in every 10,000 die in the first 24 hours of life.

I also use death-certificate data for the mortality analysis, also provided publicly by the Spanish National Statistical Institute. They record information on each registered death in Spain annually, including gender, country of citizenship, year of birth, and age at the time of death. I use two different samples: deaths by age 5 of individuals born in years 2000-2009, and deaths by age 1 of individuals born in 2000-2013. The reason to extend the sample back to 2000 is to try and increase the number of observations in the Indian sample, given the low prevailing mortality rates. I also run the analysis on a subsample restricted to children born after 2006, in order to make the sample more comparable with the analysis of sex ratios and health at birth. I combine the two mortality data sets with the birth-certificate data for the same cohorts, by age of birth, sex and country of citizenship, in order to be able to construct mortality rates. I include multiple births in the mortality analysis, since they are not specified in the deathcertificate data.

\section{Sex ratios at birth}

This section presents evidence on the number of boys born per 100 girls, for parents born in Spain versus the main immigrant source countries, with a focus on India-born parents. I also present sex ratios at birth by parity (birth-order). First I show descriptive figures that illustrate the main facts, and then I turn to regression results in order to test for the statistical significance of the differences between groups.

\subsection{Sex ratios at birth by country of origin of the parents}

Figure 1 shows the number of boys born per 100 girls, for different subgroups. In the full sample, there are 107 boys born per 100 girls. This is within the range considered "biologically normal" (Hesketh and Xing 2006). The ratio is 107 in the subsample of parents who are both Spain-born, and also among all foreign-born parents. I then show separate columns for China and India, two of the countries with highest reported sex ratios at birth. I find that Chinese parents have almost 108 boys per hundred girls, only very slightly above the average. However, the sex ratio is abnormally high among 
Indian families, reaching almost $119 .{ }^{4}$ I find no significant time trend in the sex ratio for Indian parents in the period of analysis. In order to provide some context, the child sex ratio in India was 109 in 2011 according to Census data ${ }^{5}$ (110 in Uttar Pradesh, the most populous state, 114 in Haryana, and 115 in Delhi). ${ }^{6}$

Figure 1. Sex ratio at birth by country of birth of the parents (number of boys per 100 girls)

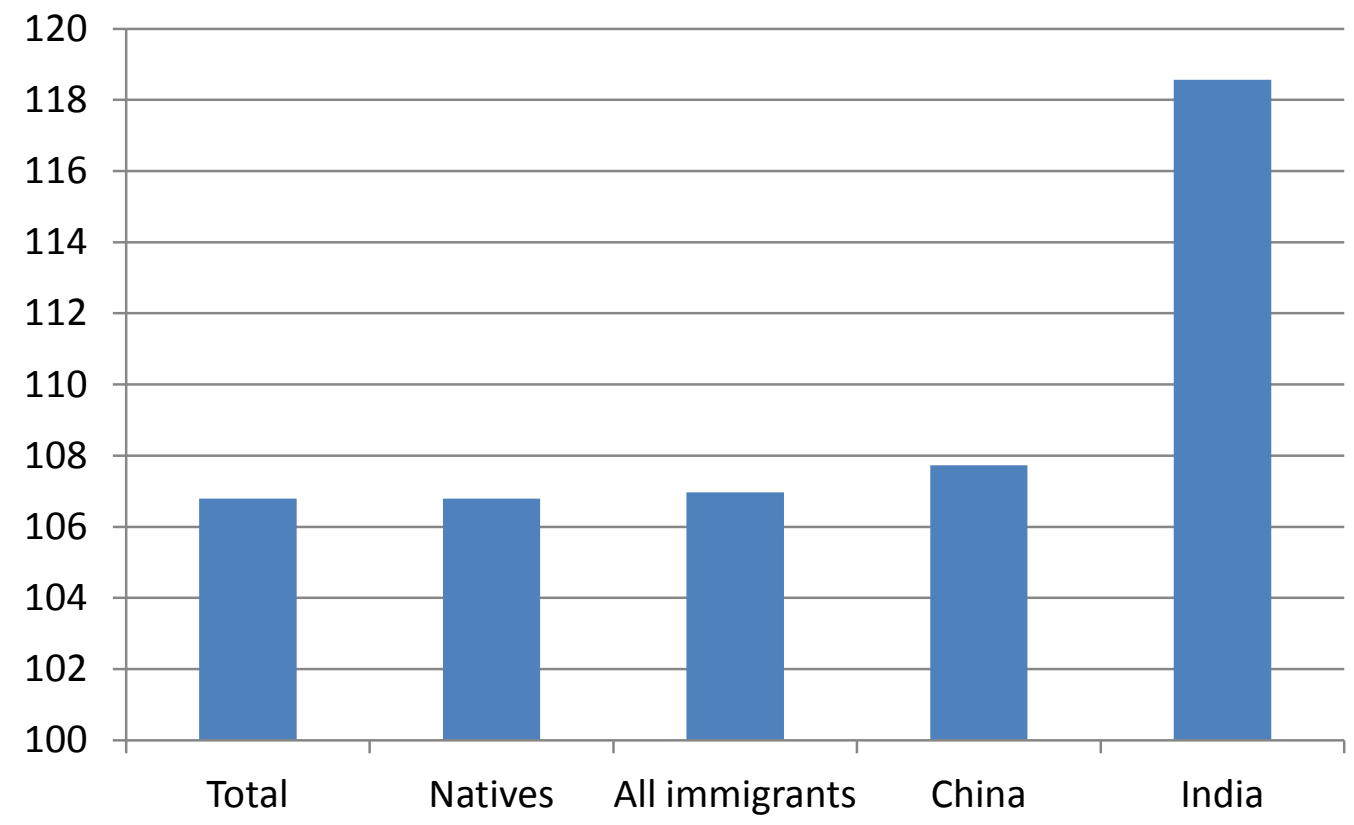

Source: Birth certificates micro data (INE), 2007-2013.

These results are confirmed in the regression analysis. I estimate a linear regression including all live births, where the dependent variable is a binary indicator for female newborns, and the main explanatory variables are two dummies indicating: both parents born outside of Spain, and both parents born in India. I also include a range of variables that control for family characteristics, in order to rule out that the observed differences

\footnotetext{
${ }^{4}$ Appendix figure A1 shows the sex ratios for the other large Asian immigrant groups, as well as the three main source countries overall. Pakistani parents have 105 boys per 100 girls, while Filipino families reach a sex ratio of 110. Romanian, Moroccan and Ecuadorian parents lie between 105 and 108.

5 Sex ratio among children aged 0 to 6, http://www.census2011.co.in/sexratio.php [Accessed on February 24, 2016]

${ }^{6}$ In the 2005-06 National Family Health Survey, the sex ratio was 107 among children under 2 years of age, and 122 among infants under one month of age (but the sample size for under one month was only 487).
} 
in sex ratios across groups can be attributed to factors other than source country: indicators for married mother and number of previous children of the mother, a thirdorder polynomial in age of the mother and age of the father, three educational attainment dummies for the mother as well as the father, a dummy for no registered father, year of birth dummies, and six indicators for size of the municipality of residence of the mother.

The regression results are presented in table 1 . The first column shows that the overall fraction of girls in the sample is $48.4 \%$, and this fraction is not significantly different among foreign-born parents overall. This is also the case after we control for family characteristics (in column 2). However, I do find (column 3) that India-born parents are significantly less likely to give birth to girls, by 2.6 percentage points (relative to both native and other foreign-born parents). The magnitude of the gap is essentially unchanged after the controls (column 4$){ }^{7}$

Table 1. Proportion of girls at birth, by country of birth of the parents

\begin{tabular}{|c|c|c|c|c|}
\hline & 1 & 2 & 3 & 4 \\
\hline Foreign-born parents & $\begin{array}{r}-0.00048 \\
(0.00073)\end{array}$ & $\begin{array}{r}0.00054 \\
(0.00108)\end{array}$ & $\begin{array}{r}-0.00032 \\
(0.00074)\end{array}$ & $\begin{array}{r}0.00069 \\
(0.00109)\end{array}$ \\
\hline Indian-born parents & & & $\begin{array}{l}-0.02579 \text { *** } \\
(0.00864)\end{array}$ & $\begin{array}{l}-0.02567 \quad \text { *** } \\
(0.00865)\end{array}$ \\
\hline Constant & $\begin{array}{r}0.4837 \text { **** } \\
(0.0003)\end{array}$ & $\begin{array}{r}0.4689 \text { *** } \\
(0.0232)\end{array}$ & $\begin{array}{r}0.4837 \text { *** } \\
(0.0003)\end{array}$ & $\begin{array}{r}0.4682 \text { *** } \\
(0.0232)\end{array}$ \\
\hline Controls & $\mathrm{N}$ & $\bar{Y}$ & $\mathrm{~N}$ & $\mathrm{Y}$ \\
\hline
\end{tabular}

N=3,209,696. Sample: Singleton live births, Spain 2007-2013. Controls: Married mother, n. of previous children, third-order polyn. in age of mother and father, three educational attainment dummies for mother and father, dummy forno registered father, year of birth dummies, and six dummies for size of the municipality of residence of the mother.

\footnotetext{
${ }^{7}$ Table A1 shows that the sex ratio is not significantly son-biased for any of the other large Asian immigrant groups. I do find a small son-bias (significant at 10\%) among Moroccan parents (of 0.37 percentage points), and a small daughter-bias ( 0.45 points) among Ecuadorian parents.
} 


\subsection{Sex ratios at birth by country and parity}

The previous literature suggests that the son-biased sex ratio is likely to be more pronounced among higher-parity births. For families with a preference for boys, having a girl is more "costly", the closer they are to their desired family size (especially if they haven't had any sons yet). Figure 2 shows the number of boys born per 100 girls, for native, Chinese, and Indian parents, by birth parity. Sex ratios are balanced in the three groups for first births. Native parents have a sex ratio of 107 at all parities. Second births for Chinese parents are very close to natives, at 107, although a son-bias emerges at third and higher parities, with 119 boys per 100 girls. This pattern is much more pronounced among Indian parents: 132 boys per 100 girls among second births, and a staggering 233 boys per 100 girls at higher parities. ${ }^{8}$

\section{Figure 2. Sex ratio at birth by country if birth of the parents and parity}

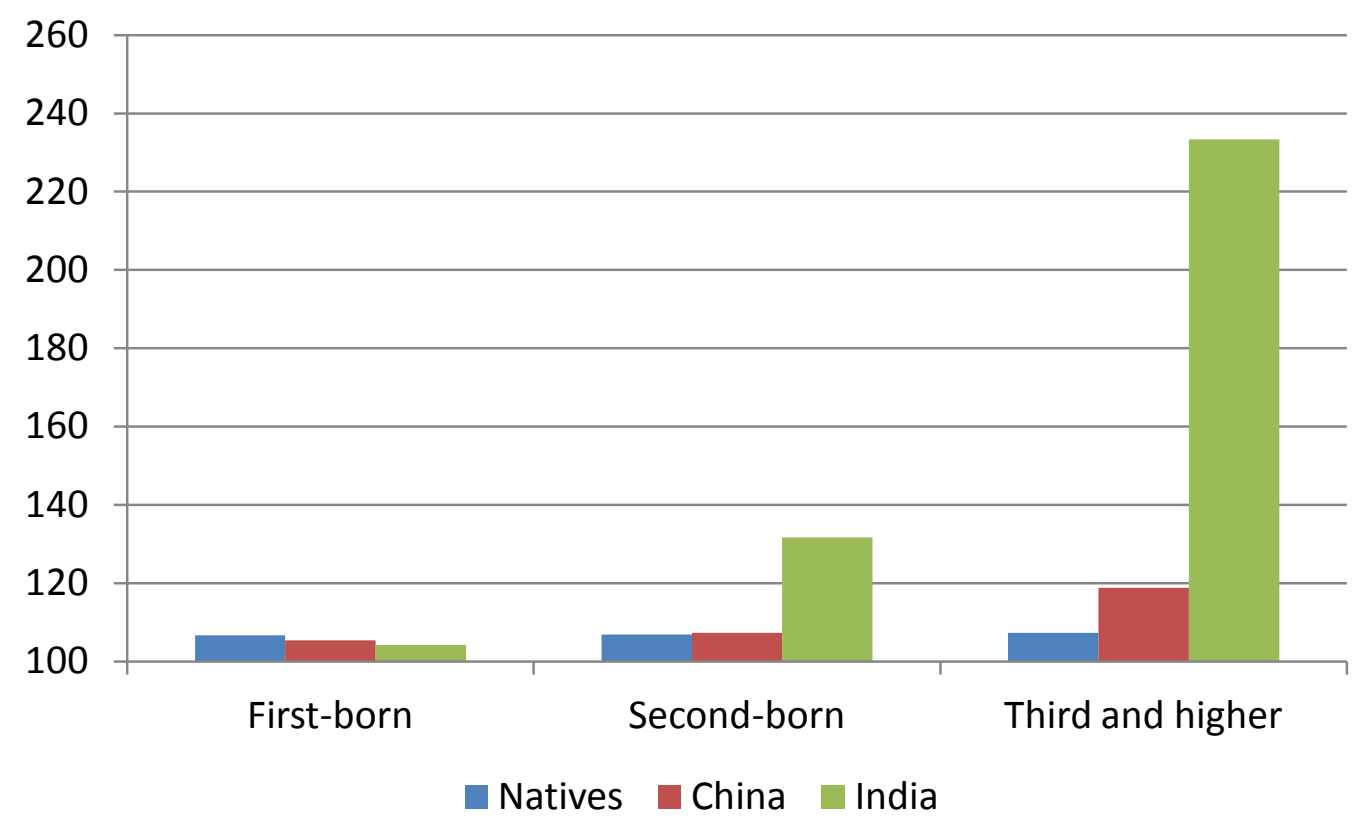

Source: Birth certificates micro data (INE), 2007-2013.

Since sample sizes by source country and parity are not large, we need standard errors in order to confirm that these patterns are statistically significant. Table 2 shows regression results where the dependent variable is again an indicator for female births,

\footnotetext{
${ }^{8}$ We observe a total of 1,959 first births to Indian parents, 1,204 second births, and only 203 third or higher-order births.
} 
and we now interact the two dummies for parents' country of birth with parity indicators. The results in the full specification (column 4) show no sex bias (relative to natives) among immigrant parents at first birth, while higher-parity births are 0.4 percentage points more likely to be female. Indian parents having their first child also display a sex ratio similar to natives. However, higher-order births to Indian parents are significantly less likely to be female, by 6.2 percentage points among second births, and 19 points among third and higher-order births. I also find that Chinese parents are significantly less likely to give birth to girls (by 3.5 percentage points) at third and higher-order parities (see table A2). ${ }^{9}$

Table 2. Proportion of girls at birth by parity and country of birth of the parents

\begin{tabular}{|c|c|c|c|c|c|c|c|}
\hline & 1 & & 2 & 3 & & 4 & \\
\hline Immig. parents $(* 1$ st-born $)$ & $\begin{array}{r}-0.00234 \\
(0.00103)\end{array}$ & $* *$ & $\begin{array}{r}-0.00136 \\
(0.00131)\end{array}$ & $\begin{array}{r}-0.00239 \\
(0.00103)\end{array}$ & $* *$ & $\begin{array}{r}-0.00143 \\
(0.00131)\end{array}$ & \\
\hline Immig. parents*2nd-born & $\begin{array}{r}0.00383 \\
(0.00164)\end{array}$ & $* *$ & $\begin{array}{r}0.00385 * * \\
(0.00164)\end{array}$ & $\begin{array}{r}0.004235 \\
(0.00164)\end{array}$ & $* *$ & $\begin{array}{r}0.00426 \\
(0.00165)\end{array}$ & $* *$ \\
\hline Immig. parents*3rd+ & $\begin{array}{r}0.00428 \\
(0.00218)\end{array}$ & $*$ & $\begin{array}{c}0.00398 * \\
(0.00220)\end{array}$ & $\begin{array}{r}0.00472 \\
(0.00219)\end{array}$ & $* *$ & $\begin{array}{r}0.00442 \\
(0.00220)\end{array}$ & $* *$ \\
\hline Indian parents $(* 1$ st-born) & & & & $\begin{array}{r}0.00818 \\
(0.01137)\end{array}$ & & $\begin{array}{r}0.00841 \\
(0.01138)\end{array}$ & \\
\hline Indian parents*2nd-born & & & & $\begin{array}{r}-0.06200 \\
(0.01832)\end{array}$ & $* * *$ & $\begin{array}{r}-0.06203 \\
(0.01832)\end{array}$ & $* * *$ \\
\hline Indian parents $* 3 \mathrm{rd}+$ & & & & $\begin{array}{r}-0.19287 \\
(0.03438) \\
\end{array}$ & $* * *$ & $\begin{array}{r}-0.19287 \\
(0.03437)\end{array}$ & $* * *$ \\
\hline Controls & $\mathrm{N}$ & & Y & $\mathrm{N}$ & & Y & \\
\hline
\end{tabular}

$\mathrm{N}=3,209,696$. Sample: Singleton live births, Spain 2007-2013. Controls: Married mother, n. of previous children, third-order polyn. in age of mother and father, three educational attainment dummies for mother and father, dummy for no registered father, year of birth dummies, and six dummies for size of the municipality of residence of the mother. 9 No other interaction of parents' country of origin and birth parity is statistically
significant (see table A2). 


\subsection{Mechanisms}

The most likely driver of the son-biased sex ratios at birth among Indian parents is sex selective abortion after sex determination. This has been shown convincingly to be the case in India (see for example Bhalotra \& Cochrane, 2010). The most common method for finding out the sex of the fetus in Spain is via the routine ultrasound that takes place at weeks 16 to 20 of the pregnancy. Some mothers may learn about it earlier, via amniocentesis, a test usually performed at weeks 14-18. Abortion is legal in Spain since 1985, under a broad range of circumstances, and about $5 \%$ of all annual abortions (more than 5,000 a year) take place after week 16 of the pregnancy ( $2 \%$ after week 20$){ }^{10}$

Conceivably, alternative (or additional) mechanisms are also possible: ${ }^{11}$

i) Sex selection at conception, via in-vitro fertilization or sperm sorting (or natural methods). However, these practices of pre-natal sex selection are not legal in Spain for non-medical reasons (as well as in many other countries), and "natural" methods have not been shown to be effective.

ii) Differential underreporting of female births. Girls could be more likely to not be registered (or could even be registered as boys). This seems highly unlikely, since birth registries in Spain are considered to be fairly complete, and the sex of the baby is reported in the documentation provided by the health center that assisted the birth.

iii) Return migration. Parents pregnant with girls could be more likely to leave Spain, and thus more boys than girls would be registered in Spain. While I cannot rule out this possibility, it's hard to think of a reason why a preference for male children would lead to the selective out-migration of families expecting a girl (except to get an abortion outside of Spain).

iv) Differential miscarriages or stillbirths after sex determination. It is conceivable that (unwanted) girls could suffer higher rates of miscarriages or stillbirths while in utero,

${ }^{10}$ González (2014) showed that the reform in the abortion law that took place in 2010 in Spain did not affect the extent of sex selection among India-born parents.

${ }^{11}$ Note that fertility stopping rules ("keep having children until you have one boy") alone cannot generate biased sex ratios at birth. 
thus leading to fewer live births. This channel is (at least partially) testable, since stillbirths are recorded in the official birth registry. ${ }^{12}$

Figure 3. Stillbirths per 1,000 births, by country of birth of the parents and gender

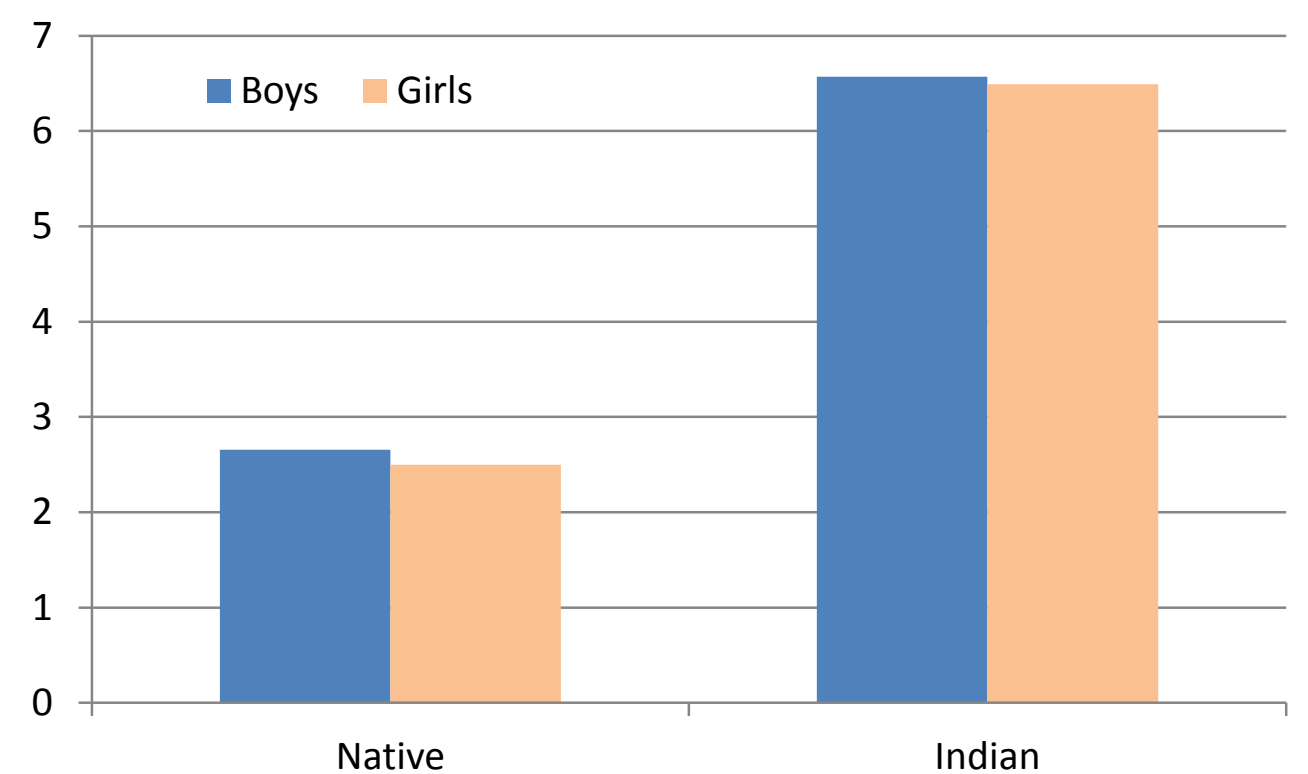

Source: Birth certificates micro data (INE), 2007-2013.

In order to test for the presence of this last mechanism, I add all stillbirths to the sample of live births. Figure 3 shows the number of stillbirths per 1,000 births, by country of birth of the parents and sex of the fetus. About 2.7 per 1,000 pregnancies of boys end in a stillbirth among native parents, very close to the 2.5 per 1,000 rate for girls. India-born parents have much higher stillbirth rates, about 6.6 per 1,000 for male fetuses, but the rate is not higher for girls (6.5). This is confirmed in the regression analysis. I estimate a set of regressions where the dependent variable is an indicator for stillbirth, and the main explanatory variables are the sex of the fetus, and the country of birth of the parents (and the interaction). The results are shown in table 3. Columns 1 and 2 show that, in general, the pregnancies of girls are less likely to end in a stillbirth. This is well known in the medical literature (Mondal et al. 2014). Stillbirth is more common among immigrant parents (column 3), but this can be attributed to the unfavorable socio-

\footnotetext{
${ }^{12}$ We use the term stillbirth to refer to "late fetal death", defined as the death in utero of a viable fetus. The fetus is considered "viable" if it weighed 500 grams or more at extraction, and registering a stillbirth is required after 180 days of gestation (almost 26 weeks).
} 
economic characteristics of immigrant families, since the coefficient reverses sign in the specification that includes the controls (column 4). Although India-born parents have higher stillbirth rates than other immigrants, this difference is not statistically significant (columns 5 and 6), and girls with Indian parents are no more likely to be stillborn than Indian-parent boys. This analysis thus allows me to rule out differential stillbirths as a source of the son-biased sex ratio among Indian parents in Spain.

Table 3. Stillbirth (per 1,000) by gender and country of birth of the parents

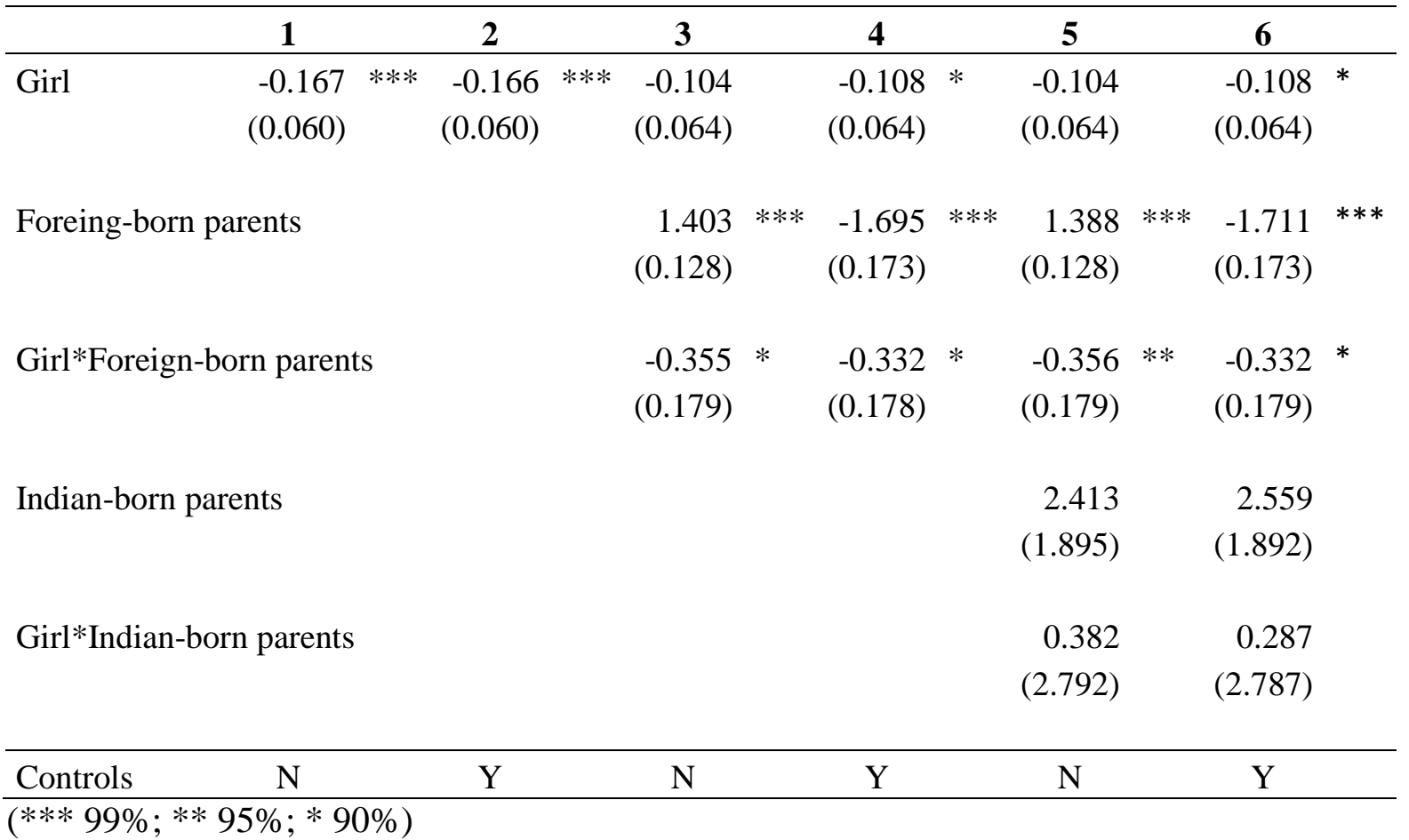

Sample: Singleton live births and stillbirths, Spain 2007-2013. Controls: Married mother, n. of previous children, third-order polyn. in age of mother and father, three educational attainment dummies for mother and father, dummy forno registered father, year of birth dummies, and six dummies for size of the municipality of residence of the mother.

\subsection{Assimilation}

If there is a cultural component in Indian parents' preference for sons over daughters, we would expect that more time in Spain would be associated with lower sex ratios at birth. While the birth certificate data does not record when the parents left their country of birth, there are some potential assimilation "markers" available, such as whether the mother or father has acquired Spanish citizenship (which requires a minimum number of years of residence in Spain), and whether an India-born mother or father has had a 
child with a Spain-born co-parent. I can thus analyze whether the degree of sexselection is less prevalent among these (presumably more assimilated) families.

Table 4. Fraction of girls at birth by parity and parent assimilation markers (Indian parents only)

\begin{tabular}{lr}
\hline & \multicolumn{1}{c}{$\mathbf{1}$} \\
\hline Second birth & $-0.05890 * * *$ \\
& $(0.01850)$ \\
Third-plus birth & -0.1832 \\
& $(0.03420)$ \\
Spanish citicenship & -0.0308 \\
(either parent) & $(0.03280)$ \\
Second birth*Citizenship & 0.0627 \\
& $(0.04330)$ \\
Third+ birth*Citizenship & $0.1160 *$ \\
& $(0.06950)$
\end{tabular}

Mixed marriage

(one parent born in Spain)

$(0.03880)$

Second birth*Mixed marriage

$(0.04780)$

Third+ birth*Mixed marriage

$0.1619 * *$

$(0.07530)$

\begin{tabular}{lrr}
\hline p-value 2nd+2nd*Assim. & 0.9244 & 0.9623 \\
p-value 3rd+3rd*Assim. & 0.272 & 0.7057 \\
\hline Controls & Y & Y \\
\hline (*** 99\%;** 95\%;* 90\%) &
\end{tabular}

$\mathrm{N}=4,419$. Sample: Singleton live births, 2007-2013, where at least one of the parents is either born in India or Indian nationality. Controls: Married mother, n. of previous children, third-order polynomial in age of mother and father, three educational attainment dummies for mother and father, dummy for no registered father, year of birth dummies, and six dummies for size of the municipality of residence of the mother.

Table 4 reports regression results where I restrict the sample to the 4,419 births where at least one of the parents is either born in India or an Indian national. The dependent variable is a dummy for girls, and the main explanatory variables are: the "assimilation" marker, and its interactions with birth-order. Column 1 shows again that second and higher-order births are severely son-biased among Indian families. Spanish citizenship 
of (at least one of) the parents is not associated with the sex ratio at first birth, but higher-order births are significantly more sex-balanced among the more assimilated families. In particular, the p-values at the bottom of the table show that Indian parents with Spanish citizenship have sex ratios at birth that are statistically indistinguishable from those of natives, at all parities. The results are very similar in column 2, where the assimilation marker is a dummy for "mixed marriages" (families where one of the parents is Spain-born).

These results provide some evidence consistent with cultural assimilation in terms of the preference for sons among Indian immigrants in Spain, although it is also possible that the results are driven by the immigrants with less of a preference for boys being more likely to acquire Spanish citizenship or marry a native.

\section{Newborn health and mortality}

The results in the previous section suggest that Indian parents in Spain are more likely to terminate the pregnancy of a female than a male fetus, reflecting a preference for sons. This preference may also be reflected in differential prenatal investments between boys and girls carried to term, which in turn could lead to gender gaps in neonatal (as well as post-neonatal) health outcomes. It is known that maternal nutrition, as well as other prenatal inputs, can have important effects on fetal development (Wu et al. 2004). In this particular case, we would have to worry only about investments taking place after sex determination (weeks 14-20 of the pregnancy).

I analyze the gender gap at birth in six different health outcomes: weeks of gestation, prematurity (less than 37 weeks of gestation), (log) birth-weight, low birthweight, very low birth-weight, and mortality within the first 24 hours after birth. The results are reported in table 5. All regressions include the full set of controls. The focus is on the coefficient for Indian-born parents, and its interaction with the sex of the newborn (last two rows). 
Table 5. Health at birth by gender and country of birth of the parents

\begin{tabular}{|c|c|c|c|c|c|c|c|c|c|c|c|c|c|c|}
\hline & Weeks & & Premature & & $\begin{array}{c}\text { Log } \\
\text { birth- } \\
\text { weight }\end{array}$ & & Low bw & & $\begin{array}{c}\text { Very low } \\
\text { bw }\end{array}$ & & $\begin{array}{c}\text { Mortality } \\
\text { 24h. }\end{array}$ & & $\begin{array}{l}\text { Health } \\
\text { Index }\end{array}$ & \\
\hline Girl & $\begin{array}{r}0.0821 \\
(0.0024)\end{array}$ & $* * *$ & $\begin{array}{r}-0.00620 \\
(0.00029)\end{array}$ & $* * *$ & $\begin{array}{l}-0.0358 \\
(0.0002)\end{array}$ & $* * *$ & $\begin{array}{r}0.0113 \\
(0.0003)\end{array}$ & $* * *$ & $\begin{array}{r}-0.00010 \\
(0.00010)\end{array}$ & & $\begin{array}{l}-0.0395 \\
(0.0265)\end{array}$ & & $\begin{array}{l}-0.0268 \\
(0.0009)\end{array}$ & $* * *$ \\
\hline $\begin{array}{l}\text { Foreing-born } \\
\text { parents }\end{array}$ & $\begin{array}{r}-0.0286 \\
(0.0057)\end{array}$ & $* * *$ & $\begin{array}{r}-0.00313 \\
(0.00063)\end{array}$ & $* * *$ & $\begin{array}{r}0.0210 \\
(0.0005)\end{array}$ & $* * *$ & $\begin{array}{l}-0.0081 \\
(0.0006)\end{array}$ & $* * *$ & $\begin{array}{r}0.00073 \\
(0.00023)\end{array}$ & $* * *$ & $\begin{array}{r}-0.1106 \\
(0.0744)\end{array}$ & & $\begin{array}{r}0.0200 \\
(0.0022)\end{array}$ & $* * *$ \\
\hline $\begin{array}{l}\text { Girl*Foreign- } \\
\text { born parents }\end{array}$ & $\begin{array}{r}-0.0267 \\
(0.0066)\end{array}$ & $* *$ & $\begin{array}{r}0.00299 \\
(0.00070)\end{array}$ & $* * *$ & $\begin{array}{r}0.0017 \\
(0.0006)\end{array}$ & $* * *$ & $\begin{array}{c}-0.0029 \\
(0.0007)\end{array}$ & $* * *$ & $\begin{array}{r}0.00002 \\
(0.00027)\end{array}$ & & $\begin{array}{r}-0.0654 \\
(0.0804)\end{array}$ & & $\begin{array}{r}0.0014 \\
(0.0025)\end{array}$ & \\
\hline $\begin{array}{l}\text { Girl*Indian- } \\
\text { born parents }\end{array}$ & $\begin{array}{l}-0.0243 \\
(0.0974)\end{array}$ & & $\begin{array}{r}0.00259 \\
(0.01020)\end{array}$ & & $\begin{array}{r}0.0019 \\
(0.0077)\end{array}$ & & $\begin{array}{r}0.0153 \\
(0.0116)\end{array}$ & & $\begin{array}{r}0.00415 \\
(0.00415)\end{array}$ & & $\begin{array}{r}2.7168 \\
(1.3078)\end{array}$ & $* *$ & $\begin{array}{l}-0.0639 \\
(0.0413)\end{array}$ & \\
\hline Controls & $\mathrm{Y}$ & & $\mathrm{Y}$ & & $\mathrm{Y}$ & & $\mathrm{Y}$ & & $\mathrm{Y}$ & & Y & & $\mathrm{Y}$ & \\
\hline
\end{tabular}

(*** 99\%;** 95\%; * 90\%)

N=3,209,697. Sample: Singleton live births, 2007-2013. Controls: Married mother, n. of previous children, third-order polynomial in age of mother and father, three educational attainment dummies for mother and father, dummy for no registered father, year of birth dummies, and six dummies for size of the municipality of residence of the mother. 
The coefficient on the dummy for Indian parents describes the health gap between boys with Indian parents and boys with immigrant parents from all other source countries. The results show that Indian boys are born with significantly fewer weeks of gestation, are almost 4 percentage points more likely to be born prematurely, have lower birthweight, and are almost 5 points more likely to weigh less than 2,500 grams at birth. The boys of Indian parents are thus significantly less healthy than the boys of both native and other immigrant parents. The only exception is neonatal mortality: the mortality rate is almost 1 per 1,000 births lower among the sons of Indian parents.

The last row of table 5 reports the estimated coefficients on the interaction between the India-born parents and the girl indicators. They capture the health gap at birth between Indian girls and boys (over and above the gender gap that's typical for parents from other source countries). I don't find evidence that the daughters of Indian parents are less healthy at birth than their sons, in terms of gestational length or birth-weight. However, they do experience a significantly higher neonatal mortality rate.

I also construct a "health at birth index" that combines the six (standardized) measures of health at birth (last column of table 5). The results confirm a significant negative coefficient for the Indian children dummy (indicating worse health), and a statistically insignificant (negative) one for the interaction of Indian and female children.

Figure 4. Prematures per 100 births, by country of birth of the parents and gender

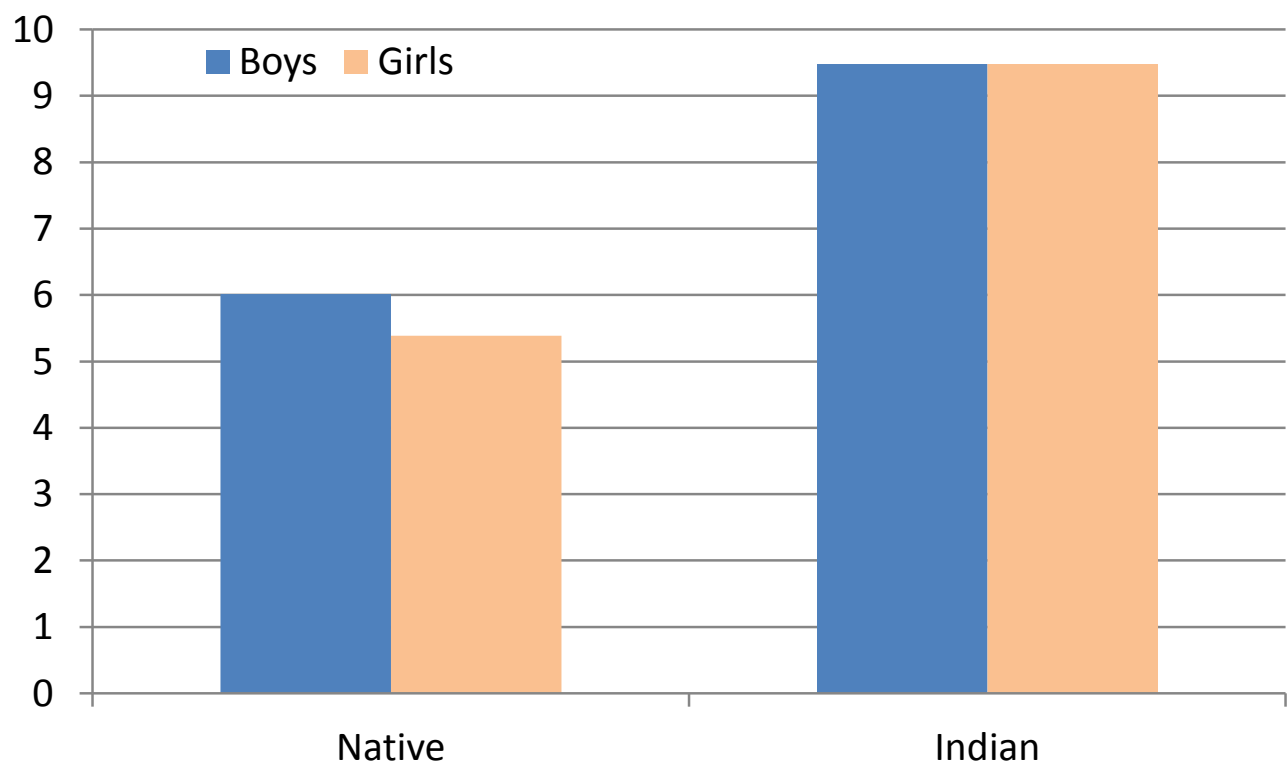


Source: Birth certificates micro data (INE), 2007-2013.

These results are summarized graphically in figures 4-6. Figure 4 shows prematurity rates for natives versus India-born parents, by sex of the newborn. More than $9 \%$ of Indian mothers give birth before the $37^{\text {th }}$ week of gestation, compared with less than $6 \%$ among native parents. There is however no difference in prematurity rates between Indian boys and girls.

\section{Figure 5. Low birth-weight per 100 births, by country of birth of the parents}

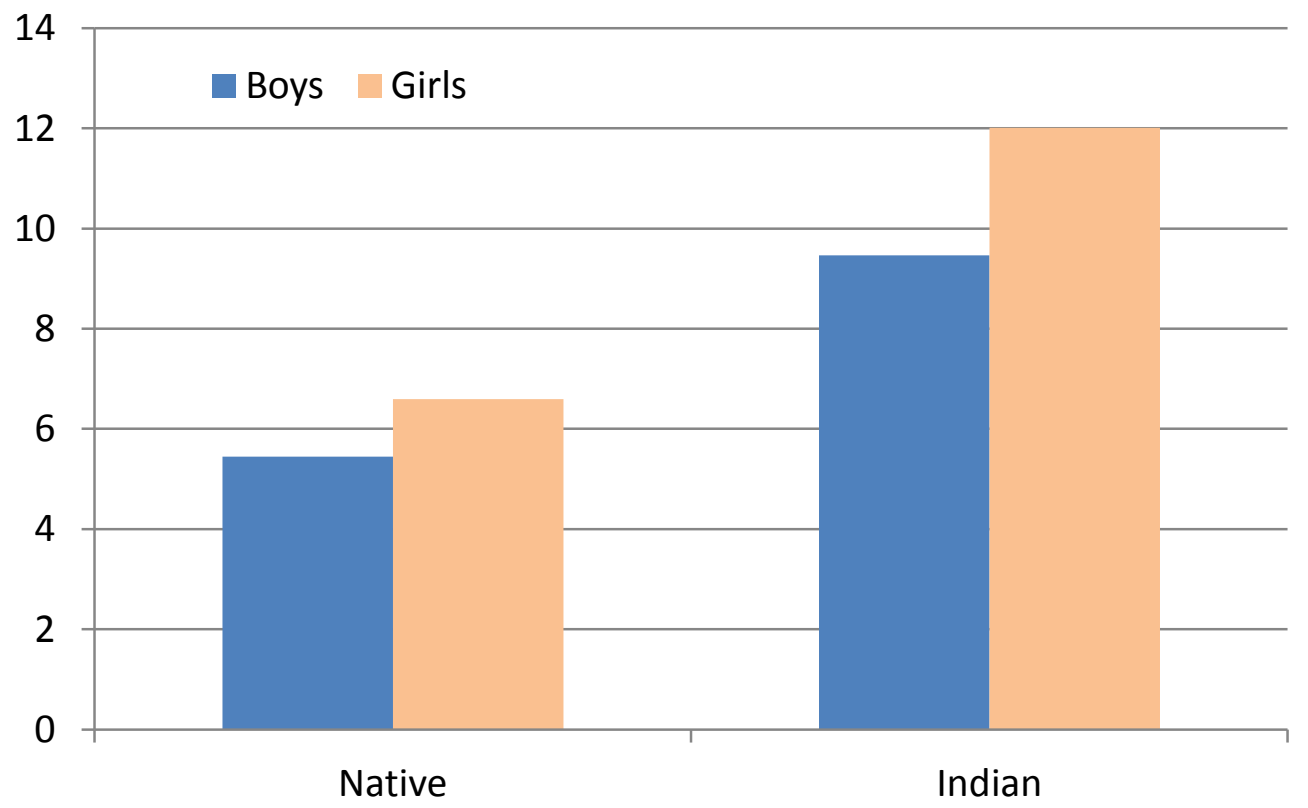

Source: Birth certificates micro data (INE), 2007-2013.

Regarding low birth-weight (figure 5), the incidence among native boys is $5.5 \%$, compared with $9.5 \%$ among boys with Indian parents. The rate is higher among Indian girls, but the gender gap is not significantly different from zero, once we take into account that native girls are also born with low birth-weight more often than native boys.

Figure 6 shows the number of newborns who do not survive the first 24 hours after birth, per 10,000 births. The mortality rate is very low among native parents, with less than 5 deaths per 10,000 live births. Indian parents, however, display a very different pattern. I do not observe any neonatal deaths among boys with Indian parents in the sample, compared with 26 per 10,000 births among Indian girls. However, we need to 
take these results with a grain of salt, since neonatal death is a very infrequent event and we only observe about 4,000 births to Indian parents. In fact, the mortality rate for girls with Indian parents is driven by only 4 deaths.

\section{Figure 6. First-day mortality per 10,000 births, by country of birth of the parents}

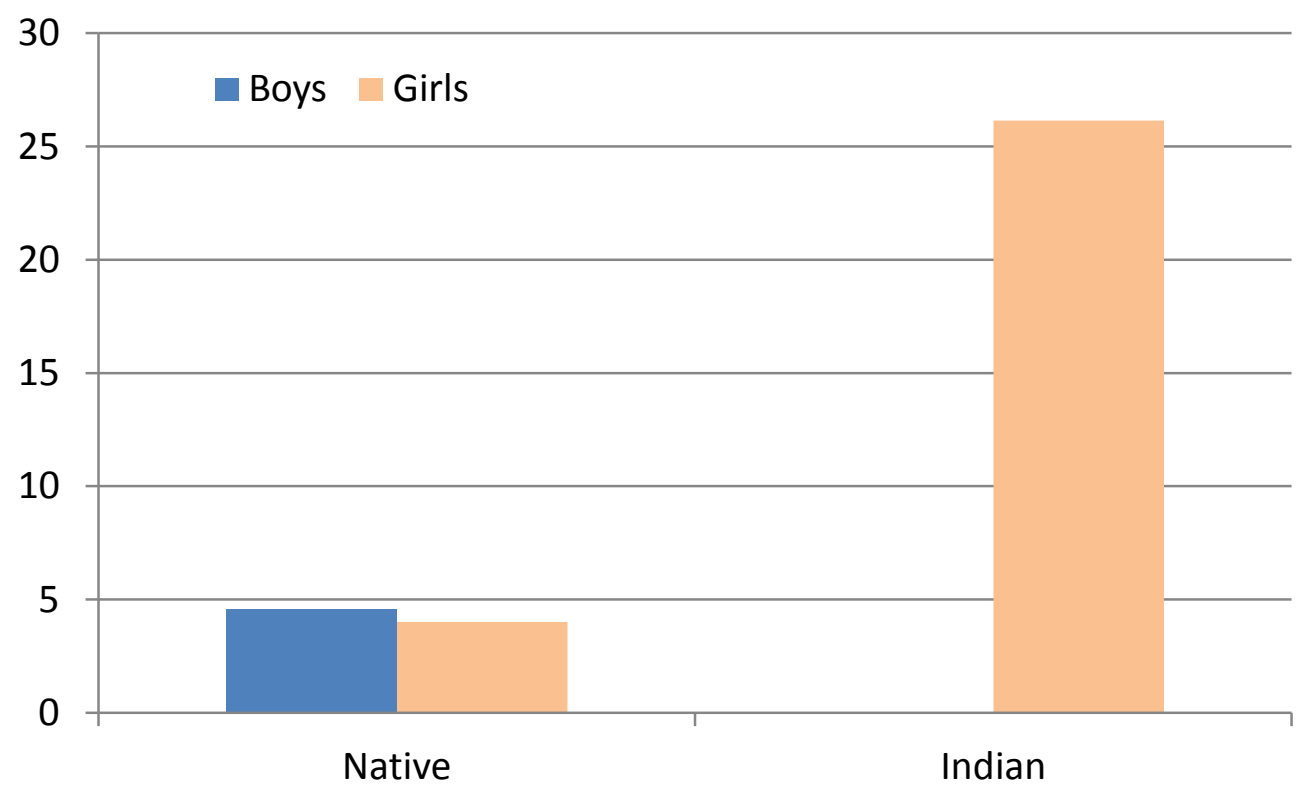

Source: Birth certificates micro data (INE), 2007-2013. The first-day mortality rate is the number of newborns who do not survive the first 24 hours after birth, per 10,000 live births.

In order to check the robustness of the first-day mortality result, as well as evaluate longer-term health outcomes, I turn to the death-certificate data. The mortality results are presented in table 6 . The first column is the closest specification to the last column of table $5,{ }^{13}$ but the results change. I now find that Indian boys have a significantly higher mortality rate than Spanish newborns, while the gender gap among Indian children is not significant. The specification in column 2 of table 6 extends the sample to earlier cohorts, and the same pattern remains.

\footnotetext{
${ }^{13}$ The death-certificate data do not report multiple births or demographic characteristics of the parents. Thus, the sample in table 6 includes multiple births, proxies the "Indian parents" variable by a dummy for Indian citizenship of the child, and includes no demographic controls.
} 
Table 6. Neonatal, infant and child mortality, by gender and country of citizenship

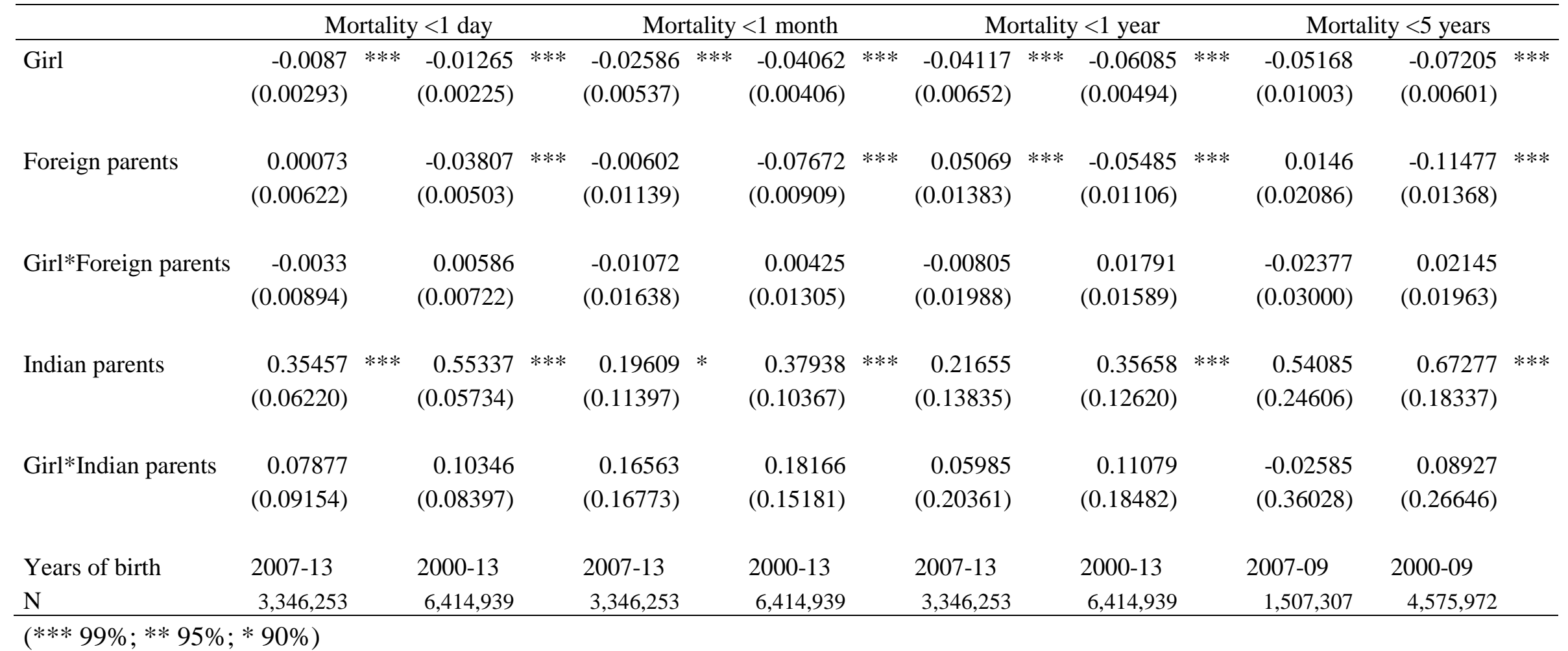

Sample: All children born in Spain in the specified years. All specifications include year of birth fixed-effects. Source: Birth and death-certificate data, 2000-2014. 
I then analyze mortality rates in the first month (neonatal mortality), first year (infant mortality), and first five years (child mortality) of life. The results are remarkably robust across age ranges and samples (table 6). Neonatal, infant and child mortality rates are significantly lower for native girls than boys. Non-Spanish children tend to have lower mortality rates than natives, but the gender gap is not significantly different. Indian boys, however, suffer significantly higher mortality rates than other immigrant children. As for Indian girls, even though their mortality rates are higher than for Indian boys, the gap is not statistically significant. These results are illustrated in figure 7 . First-month mortality is high for both Indian boys and girls, and though it is higher for girls, the difference is not significant. ${ }^{14}$

\section{Figure 7. Neonatal mortality per 10,000 births, by country of citizenship}

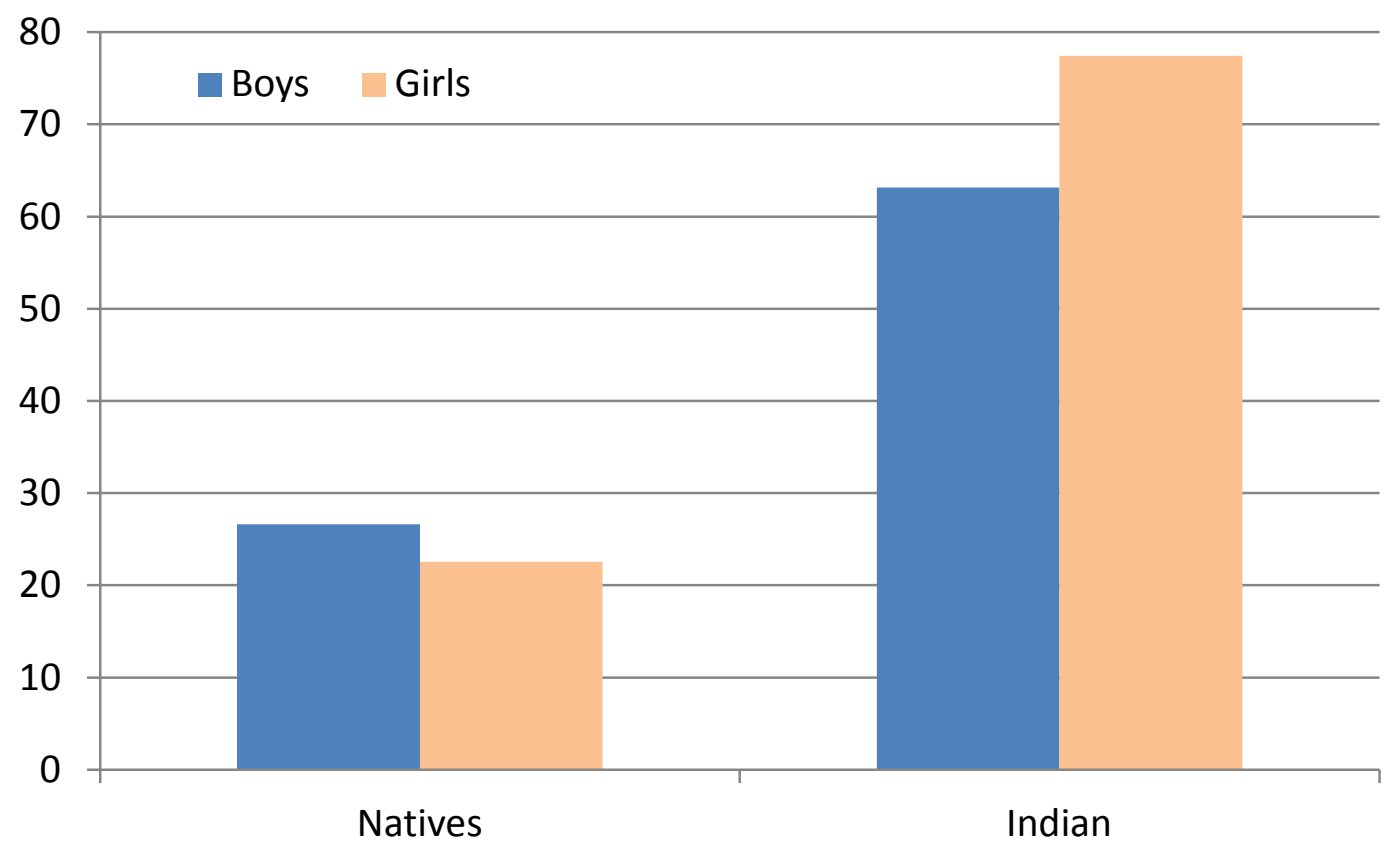

Source: Birth certificates micro data (INE), 2000-2013, and death-certificate micro data (INE), 2000-2014. The neonatal mortality rate is the number of newborns who do not survive the first month after birth, per 10,000 live births.

To summarize, I find that the children of Indian parents in Spain are significantly less healthy at birth than the children of native parents, as well as those of other immigrants in Spain, as measured by gestational length and birth-weight. They also suffer significantly higher neonatal, infant, and child mortality rates. I do not find that Indian

\footnotetext{
${ }^{14}$ I observe 15 deaths of Indian girls during the first month of life in the full sample.
} 
girls are less healthy than Indian boys at birth, and their subsequent mortality rates are not significantly higher. In the next section, I discuss the extent to which these results imply that Indian parents do not discriminate against girls in terms of pre- or post-natal investments.

\section{Interpreting the results}

Given the evidence that Indian parents appear to have strong preferences for sons over daughters, it would be useful to know whether they are also investing less in girls that are carried to term. In order to do that, I propose a simple framework for thinking about the role of prenatal investments. Assume that the health at birth production function is linear in maternal (pre-pregnancy) endowments $(m)$, prenatal investments $(I)$, and a random, mean zero component $(\varepsilon)$, uncorrelated with $m$ and $I$ :

$$
h_{i}=\alpha+\beta_{1} m_{i}+\beta_{2} I_{i}+\varepsilon_{i}
$$

For simplicity, I ignore a possible interaction term between $m$ and $I$. Parameters $\beta_{1}$ and $\beta_{2}$ are positive (or zero). Assume further that some Indian female fetuses are aborted, so that, for Indian parents expecting a girl, $h$ is observed only with probability $p$ (with probability 1 for all other pregnancies). The main results of the paper refer to empirical estimates of $p$ (section 3), as well as the average differences in $h$ between non-Indian and Indian boys, and between Indian boys and girls, conditional on live birth (section 4). We want to learn about what these results imply, regarding potentially low prenatal investments (I) among Indian parents.

Let's think first about the health gap between Indian and native (or other immigrant) boys. In this framework, the health gap at birth between Indian and other boys can come only from two sources: differences in maternal endowments $(m)$, and different prenatal investments $(I)$. We can try and estimate empirically the relative contribution of each of these components. 
Table 7. Mother's endowments by gender and country of birth of the parents

\begin{tabular}{|c|c|c|c|c|c|c|c|c|}
\hline \multirow[b]{2}{*}{ Girl } & $\begin{array}{c}\text { Mother } \\
\text { primary } \\
\text { plus } \\
\end{array}$ & $\begin{array}{c}\text { Mother } \\
\text { secondary } \\
\text { plus } \\
\end{array}$ & $\begin{array}{c}\text { Mother } \\
\text { university }\end{array}$ & $\begin{array}{l}\text { Mother's } \\
\text { age }\end{array}$ & $\begin{array}{c}\text { Father } \\
\text { primary } \\
\text { plus } \\
\end{array}$ & $\begin{array}{c}\text { Father } \\
\text { secondary } \\
\text { plus }\end{array}$ & \multicolumn{2}{|c|}{$\begin{array}{c}\text { Father } \\
\text { university }\end{array}$} \\
\hline & $\begin{array}{r}0.0008 * \\
(0.0004)\end{array}$ & $\begin{array}{r}0.0005 \\
(0.0005)\end{array}$ & $\begin{array}{r}-0.0008 \\
(0.0005)\end{array}$ & $\begin{array}{r}0.0070 * \\
(0.0043)\end{array}$ & $\begin{array}{r}-0.0001 \\
(0.0004)\end{array}$ & $\begin{array}{r}-0.0006 \\
(0.0006)\end{array}$ & $\begin{array}{r}-0.0013 \\
(0.0005)\end{array}$ & $* *$ \\
\hline $\begin{array}{l}\text { Foreing-born } \\
\text { parents }\end{array}$ & $\begin{array}{l}-0.1911 * * * \\
(0.0012)\end{array}$ & $\begin{array}{l}-0.1933 * * * \\
(0.0012)\end{array}$ & $\begin{array}{l}-0.1285 \quad * * * \\
(0.0009)\end{array}$ & $\begin{array}{l}-1.2312 \text { *** } \\
(0.0115)\end{array}$ & $\begin{array}{l}-0.1655 \text { *** } \\
(0.0012)\end{array}$ & $\begin{array}{l}-0.1455 * * * \\
(0.0012)\end{array}$ & $\begin{array}{r}-0.0919 \\
(0.0009)\end{array}$ & $* * *$ \\
\hline $\begin{array}{l}\text { Girl*Foreign- } \\
\text { born parents }\end{array}$ & $\begin{array}{r}0.0014 \\
(0.0014)\end{array}$ & $\begin{array}{r}-0.0003 \\
(0.0013)\end{array}$ & $\begin{array}{r}0.0009 \\
(0.0009)\end{array}$ & $\begin{array}{r}-0.0099 \\
(0.0133)\end{array}$ & $\begin{array}{r}0.0024 * \\
(0.0014)\end{array}$ & $\begin{array}{r}0.0024 * \\
(0.0014)\end{array}$ & $\begin{array}{r}0.0009 \\
(0.0009)\end{array}$ & \\
\hline $\begin{array}{l}\text { Indian-born } \\
\text { parents }\end{array}$ & $\begin{array}{l}-0.1028 * * * \\
(0.0118)\end{array}$ & $\begin{array}{l}-0.0992 * * * \\
(0.0103)\end{array}$ & $\begin{array}{l}-0.0342 \quad * * * \\
(0.0070)\end{array}$ & $\begin{array}{l}-0.6915 \text { *** } \\
(0.0894)\end{array}$ & $\begin{array}{l}-0.1065 \text { *** } \\
(0.0118)\end{array}$ & $\begin{array}{l}-0.1119 * * * \\
(0.0099)\end{array}$ & $\begin{array}{r}-0.0206 \\
(0.0064)\end{array}$ & $* * *$ \\
\hline $\begin{array}{l}\text { Girl*Indian- } \\
\text { born parents }\end{array}$ & $\begin{array}{r}0.0000 \\
(0.0174)\end{array}$ & $\begin{array}{r}-0.0191 \\
(0.0149)\end{array}$ & $\begin{array}{r}-0.0096 \\
(0.0100)\end{array}$ & $\begin{array}{r}-0.0539 \\
(0.1336)\end{array}$ & $\begin{array}{r}-0.0073 \\
(0.0174)\end{array}$ & $\begin{array}{r}-0.0221 \\
(0.0143)\end{array}$ & $\begin{array}{r}-0.0123 \\
(0.0091)\end{array}$ & \\
\hline Controls & $\mathrm{Y}$ & $\mathrm{Y}$ & $\mathrm{Y}$ & $\mathrm{Y}$ & $Y$ & $Y$ & $\mathrm{Y}$ & \\
\hline
\end{tabular}

(*** 99\%; ** 95\%;*90\%)

Sample: Singleton live births, 2007-2013 (N=3,209,696). Controls: Married mother, number of previous children, third-order polynomial in age of mother and father, three educational attainment dummies for mother and father, dummy for no registered father, year of birth dummies, and six dummies for size of the municipality of residence of the mother. The regressions for education of the mother (father) drop the mother (father) education dummies from the controls, while the regression for mother's age drops the polynomial in mother's age from the controls. 
Unfortunately, the birth-certificate data do not include information on the health of the mother (height, weight, etc). As proxies for maternal endowments, I use mother's age, mother's educational attainment, and father's educational attainment. Education is meant to capture socio-economic status, and higher parental education is associated with better neonatal health. Regarding mother's age, newborn health is on average worse when the mother is either very young (under 20) or very old (over 35). Regression results in table 7 compare parents' characteristics for native versus India-born parents, and for parents giving birth to boys versus girls.

The second row shows that immigrant parents are on average younger and less educated than natives. The second-to-last row indicates that this is particularly pronounced among Indian parents: India-born mothers are 0.7 years younger, compared with other foreign-born mothers. They are also 10 percentage points less likely to have secondary education. These results suggest that low maternal endowments (in particular, low socio-economic status) are likely to be a contributing factor to the low health of infants with Indian parents.

Table 8. Prenatal investments by gender and country of birth of the parents

\begin{tabular}{|c|c|c|}
\hline & Home birth & $\begin{array}{l}\text { Jnassisted } \\
\text { birth }\end{array}$ \\
\hline Girl & $\begin{array}{r}0.00030 \text { *** } \\
(0.00008)\end{array}$ & $\begin{array}{r}0.00011 \text { *** } \\
(0.00003)\end{array}$ \\
\hline
\end{tabular}

Foreing-born parents

$\begin{array}{rr}0.00099 * * * & 0.00021 * * * \\ (0.00019) & (0.00007)\end{array}$

Girl*Foreign-born parents

$\begin{array}{rr}0.00001 & -0.00001 \\ (0.00022) & (0.00009)\end{array}$

Indian-born parents

$\begin{array}{rr}0.00146 & -0.00021 \\ (0.00183) & (0.00055)\end{array}$

Girl*Indian-born

$\begin{array}{rrr}\text { parents } & -0.00280 & 0.00072 \\ & (0.00234) & (0.00108)\end{array}$

\begin{tabular}{lll}
\hline Controls & Y & Y \\
$(* * * 99 \% ; * * 95 \% ; * 90 \%)$ &
\end{tabular}

N=3,209,697. Sample: Singleton live births, 2007-2013. Controls: Married mother, 
number of previous children, third-order polynomial in age of mother and father, three educational attainment dummies for mother and father, dummy forno registered father, year of birth dummies, and six dummies for size of the municipality of residence of the mother.

In table 8 , I show the results for parental investments. In the absence of information about prenatal care or health behaviors during pregnancy, I use an indicator for births taking place outside of a health facility (including home births), and an indicator for births not assisted by a health professional. I find that foreign-born parents are more likely to give birth outside of a health center and without medical assistance. However, this pattern is no more pronounced among Indian mothers. Thus, I find no evidence of low parental investments in Indian boys, compared with other male newborns with immigrant parents.

In sum, my results suggest that the observed poor neonatal health outcomes among Indian boys are more likely to result from poor maternal endowments (low socioeconomic status, possibly poor health) than low prenatal investments, with the caveat of the low quality of my observed measures of both endowments and investments.

Let's think next about the health gap between boys and girls with Indian parents (I now condition on Indian parents and drop the $i$ subscript for simplicity):

$E[h \mid g=1]-E[h \mid g=0]=$

$\beta_{1}(E[m \mid g=1]-E[m \mid g=0])+\beta_{2}(E[I \mid g=1]-E[I \mid g=0])$,

where $g$ is an indicator for girls. Since we are not conditioning on live birth, this expression refers to all conceptions. As a result, the gender of the fetus can be treated as random, so that $E[m \mid g=1]=E[m \mid g=0]=E[m]$. Therefore, any health gap at birth between all conceived Indian male and female fetuses can only be attributed to differential prenatal investments:

$E[h \mid g=1]-E[h \mid g=0]=\beta_{2}(E[I \mid g=1]-E[I \mid g=0])$

However, the gaps that I estimated in section 4 were conditional on live birth. Note that:

$E[y \mid g=1$, birth=1] $-E[y \mid g=0$, birth=1] $=E[y \mid g=1$, birth=1] $-E[y \mid g=0]=$

$\beta_{1}(E[m \mid g=1$, birth $=1]-E[m])+\beta_{2}(E[I \mid g=1$, birth $=1]-E[I \mid g=0])$.

The observed health gap between Indian girls and boys, thus, can be decomposed into two terms. The first term is the degree of selection in mothers' endowments (the extent 
to which the mothers who do not terminate the pregnancies of girls differ from the average, in pre-pregnancy dimensions that matter for newborn health). The second term is the different propensity to invest (pre-natally) in boys versus girls, for the mothers who do not abort girls compared to the mothers of boys. These components are mediated by their respective coefficients, which capture the extent to which mothers' endowments and investments matter for newborn health.

The second term can be decomposed further into: $E[I \mid g=1$, birth $=1]-E[I \mid g=0]=(E[I \mid g=1]-E[I \mid g=0])+(E[I \mid g=1$, birth $=1]-E[I \mid g=1])$, where the first part is the different propensity to invest in boys versus girls in the population of all conceptions, including those not carried to term, and the second component represents selection into prenatal investments, i.e. the extent to which mothers who do not abort female fetuses invest in them differently from the average Indian mother carrying a girl (including those who decide to not carry them to term).

Can we sign these three terms a priori? Selection in mothers' endowments is hard to sign. Evidence from India suggests that sex selection is prevalent among wealthy and poor, educated and uneducated parents (Srinivasan 2004, Das Guspta 1987). The different propensity to invest in girls versus boys is probably negative (or zero), indicating the preference for sons among Indian parents, but selection into prenatal investments is likely to be positive, since the parents who choose not to abort girls are probably the ones with a weaker preference for boys, and thus are likely to invest more than the average in girls.

We can again (partially) estimate these different components from the data (Tables 7 and 8). Regarding selection in mother's endowments, the last row of table 7 shows that the educational attainment of Indian parents who give birth to boys versus girls are not significantly different from one another, suggesting no selection in parental schooling. More educated Indian parents are no less (or more) likely to practice selective abortion than less-educated ones. Also, Indian mothers giving birth to girls are not significantly younger (or older) than the mothers of boys.

Table 8 shows that girls born to Indian parents are no less likely to be born at home, or unassisted by a health professional. This is consistent with, either no differential propensity to invest in boys versus girls, or a differential propensity being compensated by positive selection among those parents choosing not to abort girls. 
These results provide a rationale for our previous finding that girls born to Indian parents are no less healthy at birth than boys with Indian parents. This is consistent with parents who on average would invest less in female than male children (because of a cultural preference for male offspring), combined with positive selection into live birth (in terms of potential investment in girls) among the parents expecting girls, so that the parents with a stronger preference for boys would be more likely to abort female fetuses.

\section{Conclusions}

In this paper, I use birth-certificate data for Spain to document extremely son-biased sex ratios at birth among Indian immigrants. I also show that the children of Indian immigrants display poor health outcomes at birth, although there is no evidence of a gender gap in newborn health or infant mortality. I provide evidence suggesting that the poor outcomes of Indian children at birth can plausibly be attributed to the poor endowments of Indian mothers. The absence of a gender gap, on the other hand, is likely driven by the fact that the parents who would invest less in girls are less likely to carry the pregnancies of girls to term (more likely to practice sex-selective abortion). ${ }^{15}$

These results imply that a reduction in the incidence of sex-selective abortions, if not driven by a decrease in the preference for boys, could lead to lower average investments in girls, and thus worse infant health (and possibly higher mortality rates) among girls. For instance, banning sex selective abortion (or prenatal sex determination), if effective, could have the unintended effect of worsening health, as well as potentially other outcomes, among (ethnic Indian) girls. ${ }^{16}$

Turning the argument around, the recent increase in the incidence of sex-selective abortions in India most likely led to higher parental investments in girls on average (for girls who were actually carried to term), and thus should have contributed to better infant health and possibly to a reduction in excess female mortality (as found by Anukriti, Bhalotra and Tam 2016). Also consistent with this argument, $\mathrm{Hu}$ and

${ }^{15}$ It is also consistent with the parental preference for boys leading to prenatal sex selection, but not to differential investments if the pregnancy is not terminated, perhaps out of a moral obligation towards the (unborn) child.

16 This argument was also made by Bharadwaj \& Lakdawale (2013) and $\mathrm{Hu}$ \& Schlosser (2015). 
Schlosser (2015) find that increases in prenatal sex selection in Indian states are associated with reductions in girls' malnutrition. ${ }^{17}$ In other words, the recent observed increase in the male to female ratio at birth in India and other countries could have contributed directly to the observed (lagged) decline in female mortality (Bongaarts \& Guilmoto 2015). ${ }^{18}$

An important caveat of this study is that the available data contain only limited information regarding the health endowments of the mother as well as prenatal investments. Moreover, the focus is on newborn health, so that future work should focus on post-neonatal parental investments and health, as well as on potential gender gaps in (health and education) outcomes among children with Indian parents after the neonatal period.

${ }^{17}$ They find no effect on girls' mortality. They do not study health at birth or pre-natal parental investments.

${ }^{18}$ Consistent with this argument, Lin, Liu \& Qian (2014) find that the introduction of sex-selective abortion in Taiwan led to lower relative neonatal female mortality rates. 


\section{References}

Abrevaya, Jason (2009) "Are there missing girls in the United States? Evidence from birth data." American Economic Journal: Applied Economics 1(2):1-34.

Almond, Douglas and Lena Edlund (2008) "Son Biased Sex Ratios in the US 2000 Census." PNAS 105(15): 5681-5682.

Almond, Douglas, Lena Edlund and Kevin Milligan (2013) "Son Preference and the Persistence of Culture: Evidence from South and East Asian Immigrants to Canada" Population and Development Review 39(1): 75-95.

Anukriti, S, Sonia Bhalotra and Hiu Tam (2016) "Missing Girls: Ultrasound Access and Excess Female Mortality” Unpublished manuscript.

Barcellos, Silvia Helena, Leandro S. Carvalho, and Adriana Lleras-Muney (2014) "Child Gender and Parental Investments in India: Are Boys and Girls Treated Differently?" American Economic Journal: Applied Economics 6(1): 157-189.

Bhalotra, Sonia and Tom Cochrane (2010) "Where Have All the Young Girls Gone? Identification of Sex Selection in India" IZA Discussion Paper No. 5381.

Bharadwaj, Prashant and Leah K. Lakdawala (2013) "Discrimination Begins in the Womb Evidence of Sex- Selective Prenatal Investments" Journal of Human Resources 48(1): 71-113.

Bongaarts, John and Christophe Z. Guilmoto (2015) "How Many More Missing Women? Excess Female Mortality and Prenatal Sex Selection, 1970-2050" Population and Development Review 41(2) : 241-269 (JUNE 2015)

Coffey, Diane (2015) "Prepregnancy body mass and weight gain during pregnancy in India and sub-Saharan Africa" PNAS 112(11): 3302-3307.

Das Gupta, Monica (1987) "Selective Discrimination against Female Children in Rural Punjab, India" Population and Development Review 13(1): 77-100.

Deaton, Angus and Jean Drèze (2009) "Food and Nutrition in India: Facts and Interpretations." Economic and Political Weekly 44 (7): 42-65.

Dubuc, Sylvie and David Coleman (2007) "An Increase in the Sex Ratio of Births to India-born Mothers in England and Wales: Evidence for Sex-Selective Abortion" Population and Development Review, 32(2): 383-400.

González, Libertad (2014) “Missing girls in Spain” Cuadernos Económicos del ICE 87.

Hesketh, Therese and Zhu Wei Xing (2006) "Abnormal sex ratios in human populations: Causes and consequences." PNAS 103(36): 13271-13275.

$\mathrm{Hu}$, Luojia and Analía Schlosser (2015) "Prenatal Sex Selection and Girls' Well-Being: Evidence from India.” Economic Journal 125(587): 1227-1261.

Jayachandran, Seema and Ilyana Kuziemko (2011) "Why Do Mothers Breastfeed Girls Less Than Boys? Evidence and Implications for Child Health in India." Quarterly Journal of Economics 126, 1485-1538. 
Jayachandran, Seema and Rohini Pande (2015) "Why Are Indian Children So Short? The Role of Birth Order and Son Preference." Working paper, Northwestern University.

Jha, Prabhat, Rahesh Kumar, Priya Vasa, Neeraj Dhingra, Deva Thiruchelvam, and Rahim Moineddin (2006) "Low female-to-male sex ratio of children born in India: National survey of 1.1 million households" Lancet 367:211-218.

Lin, Ming-Jen, Jin-Tan Liu and Nancy Qian (2014) "More Missing Women, Fewer Dying Girls: The Impact of Abortion on Sex Ratios at Birth and Excess Female Mortality in Taiwan" Journal of European Economic Association 12(4).

Mondal, Debapriya, Tamara S Galloway, Trevor C Bailey, and Fiona Mathews (2014) "Elevated risk of stillbirth in males: systematic review and meta-analysis of more than 30 million births". BMC Medicine 12:220.

Oster (2009a) "Proximate Sources of Population Sex Imbalance in India" Demography 46(2): 325-339.

Oster (2009b) "Does Increased Access Increase Equality? Gender and Child Health Investments in India" Journal of Development Economics 89(1): 62-76.

Proos, L.A., Y. Hofvander, K. Wennqvist, T. Tuvemo (1992) “A longitudinal study on anthropometric and clinical development of Indian children adopted in Sweden" Upsala Journal of Medical Science 97: 93-106.

Sen, Amartya (1990) "More than 100 Million Women Are Missing" The New York Review of Books.

Sen, Amartya (1992) "Missing women: social inequality outweighs women's survival advantage in Asia and north Africa" British Medical Journal v304 n6827 p587(2).

Sen, Amartya (2003) "Missing women - revisited. Reduction in female mortality has been counterbalanced by sex selective abortions" British Medical Journal 327:1297-8.

Sharada Srinivasan (2004) "Daughters or dowries? The changing nature of dowry practices in south India." World Development 33(4): 593-615.

Tarozzi (2008) "Growth Reference Charts and the Nutritional Status of Indian Children" Economics and Human Biology 6(3): 455-468.

Tarozzi, Alessandro (2012) "Some Facts about Boy vs. Girl Health Indicators in India: 1992 to 2005” CESifo Economic Studies 58(2): 296-321.

Wu, Gouyao, Fuller W. Bazer, Timothy A. Cudd, Cynthia J. Meininger, and Thomas E. Spencer (2004) "Maternal Nutrition and Fetal Development" Journal of Nutrition 134(9): 2169-2172. 
Figure A1. Sex ratio at birth by country of birth of the parents (number of boys per 100 girls)

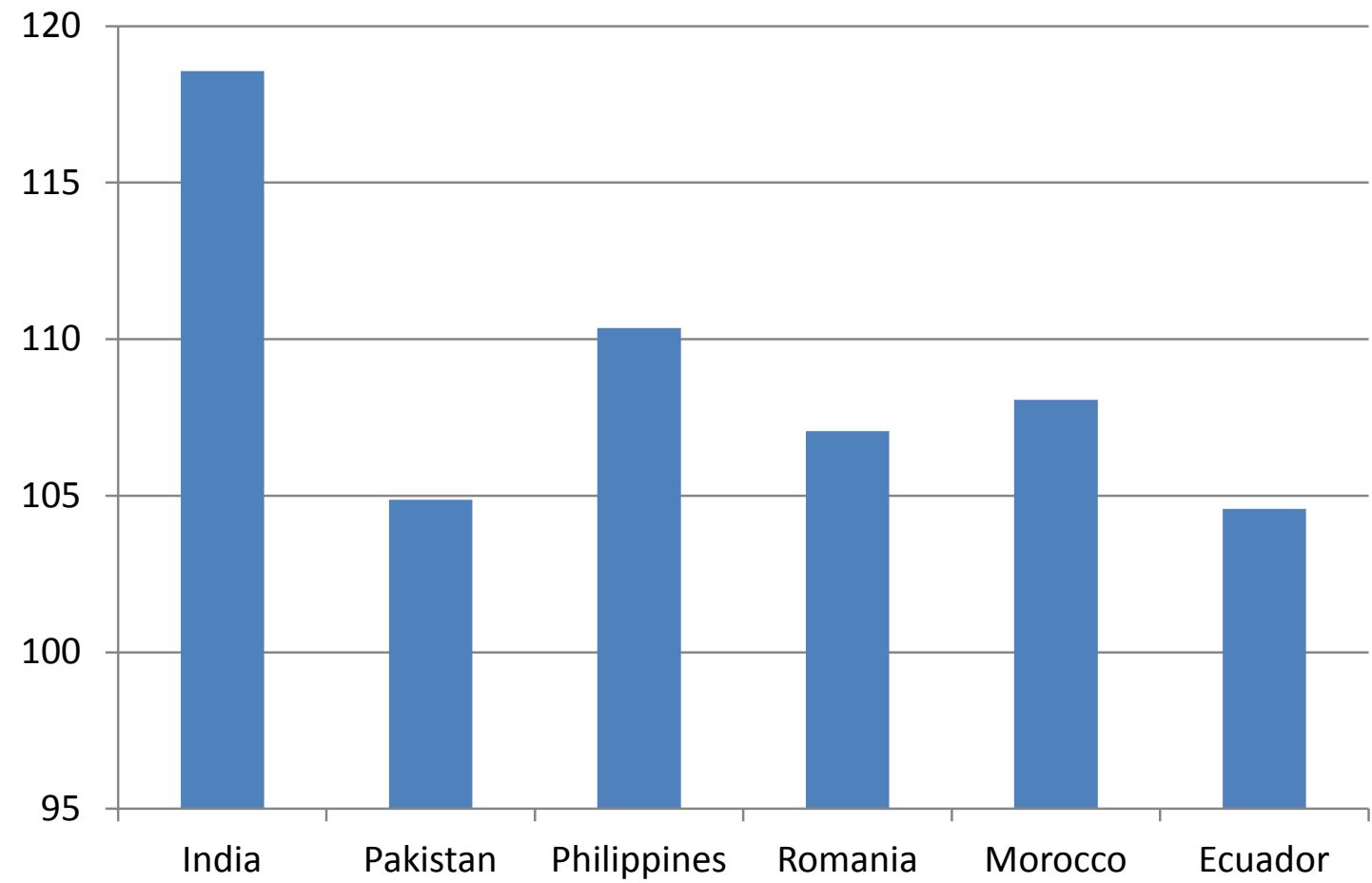


Table A1. Proportion of girls at birth, by country of birth of the parents, additional source countries

\begin{tabular}{lrr}
\hline & $\mathbf{1}$ & \multicolumn{1}{c}{$\mathbf{2}$} \\
\hline Foreign-born parents & 0.0007 & 0.0013 \\
& $(0.0010)$ & $(0.0013)$
\end{tabular}

Indian-born parents

$-0.0268 * * * \quad-0.0266 * * *$

$(0.0087) \quad(0.0087)$

China-born parents

$\begin{array}{rr}-0.0029 & -0.0020 \\ (0.0032) & (0.0032)\end{array}$

Pakistan-born parents

$\begin{array}{rr}0.0038 & 0.0039 \\ (0.0062) & (0.0620)\end{array}$

Philippines-born

parents

$-0.0089$

$-0.0091$

$(0.0085)$

$(0.0085)$

Romania-born parents

$-0.0014$

$-0.0008$

$(0.0022)$

$(0.0022)$

Morocco-born parents

\begin{tabular}{|c|c|}
\hline$-0.0037 * *$ & -0.0033 \\
\hline (0.0016) & $(0.0017)$ \\
\hline
\end{tabular}

Ecuador-born parents
0.0045
$0.0047 *$
(0.0026)
(0.0026)

\begin{tabular}{ll}
\hline Controls & $\mathrm{N}$ \\
\hline$(* * 99 \% ; * * 95 \% ; * 90 \%)$ & $\mathrm{Y}$ \\
$\mathrm{N}=3,209,697$ &
\end{tabular}

Sample: Singleton live births, 2007-2013.

Controls: Married mother, n. of previous children, third-order polynomial in age of mother and father, three educational attainment dummies for mother and father, dummy forno registered father, year of birth dummies, and six dummies for size of the municipality of residence of the mother. 
Table A2. Proportion of girls at birth by parity and country of birth of the parents, additional source countries

\begin{tabular}{|c|c|c|c|}
\hline & Coefficient & & $\begin{array}{r}\text { (Standard } \\
\text { error) }\end{array}$ \\
\hline Second-born & -0.00096 & & $(0.00068)$ \\
\hline Third+ & -0.00247 & $* *$ & $(0.00117)$ \\
\hline Immigrant & -0.00131 & & $(0.00161)$ \\
\hline Immigrant*2nd & 0.00532 & $* *$ & $(0.00229)$ \\
\hline Immigrant $* 3 \mathrm{rd}$ & 0.00618 & $* *$ & $(0.00310)$ \\
\hline Indian & 0.00797 & & $(0.01142)$ \\
\hline Indian*2nd & -0.06307 & $* * *$ & $(0.01838)$ \\
\hline Indian*3rd & -0.19462 & $* * *$ & $(0.03444)$ \\
\hline Romanian & 0.00013 & & $(0.00289)$ \\
\hline Romanian*2nd & -0.00097 & & $(0.00496)$ \\
\hline Romanian*3rd & -0.00289 & & $(0.00801)$ \\
\hline Moroccan & -0.00302 & & $(0.00239)$ \\
\hline Moroccan*2nd & -0.00124 & & $(0.00368)$ \\
\hline Moroccan*3rd & -0.00134 & & $(0.00434)$ \\
\hline Ecuador & 0.00442 & & $(0.00425)$ \\
\hline Ecuador*2nd & -0.00241 & & $(0.00597)$ \\
\hline Ecuador*3rd & 0.00184 & & (0.00699) \\
\hline China & 0.00588 & & $(0.00453)$ \\
\hline China*2nd & -0.00946 & & $(0.00684)$ \\
\hline China*3rd & -0.03465 & $* * *$ & $(0.00986)$ \\
\hline Pakistan & 0.00380 & & $(0.00940)$ \\
\hline Pakistan*2nd & -0.00895 & & $(0.01492)$ \\
\hline Pakistan*3rd & 0.00704 & & $(0.01489)$ \\
\hline Philippines & -0.01086 & & $(0.01120)$ \\
\hline Phil.*2nd & 0.01168 & & $(0.01925)$ \\
\hline Phil.*3rd & -0.01134 & & $(0.02633)$ \\
\hline
\end{tabular}

Sample: Singleton live births, 2007-2013.

Controls: Married mother, n. of previous children, third-order polyn. in age of mother and father, three educational attainment dummies for mother and father, dummy for no registered father, year of birth dummies, and six dummies for size of the municipality of residence of the mother. 